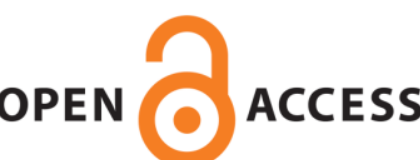

UWS Academic Portal

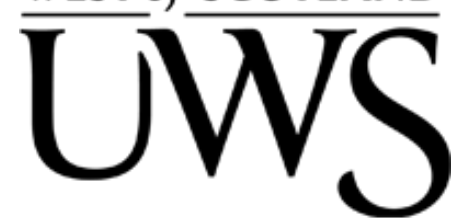

\title{
An analysis of core competence and unique value proposition as normative entrepreneurship elements
}

Dahle, Yngve; Toscher, Ben; Duc, Anh Nguyen; Steinert, Martin; Reuther, Kevin

Published in:

2019 IEEE International Conference on Engineering, Technology and Innovation (ICE/ITMC)

DOI:

10.1109/ICE.2019.8792669

Published: 12/08/2019

Document Version

Peer reviewed version

Link to publication on the UWS Academic Portal

Citation for published version (APA):

Dahle, Y., Toscher, B., Duc, A. N., Steinert, M., \& Reuther, K. (2019). An analysis of core competence and unique value proposition as normative entrepreneurship elements. In 2019 IEEE International Conference on Engineering, Technology and Innovation (ICE/ITMC) IEEE. https://doi.org/10.1109/ICE.2019.8792669

\section{General rights}

Copyright and moral rights for the publications made accessible in the UWS Academic Portal are retained by the authors and/or other copyright owners and it is a condition of accessing publications that users recognise and abide by the legal requirements associated with these rights.

Take down policy

If you believe that this document breaches copyright please contact pure@uws.ac.uk providing details, and we will remove access to the work immediately and investigate your claim. 
"Dahle, Y., Toscher, B., Duc, A. N., Steinert, M., \& Reuther, K. (2019). An analysis of core competence and unique value proposition as normative entrepreneurship elements. In 2019 IEEE International Conference on Engineering, Technology and Innovation (ICE/ITMC) IEEE. https:// doi.org/10.1109/ICE.2019.8792669 (c) (c) 2019 IEEE. Personal use of this material is permitted. Permission from IEEE must be obtained for all other uses, in any current or future media, including reprinting/republishing this material for advertising or promotional purposes, creating new collective works, for resale or redistribution to servers or lists, or reuse of any copyrighted component of this work in other works." 


\section{An analysis of Core Competence and Unique Value Proposition as normative entrepreneurship elements}

\author{
Yngve Dahle \\ Norwegian University of Science and \\ Technology (NTNU) \\ Faculty of Engineering Science and \\ Technology (IVT) \\ Norway \\ yngve.dahle@ntnu.no \\ Martin Steinert \\ Norwegian University of Science and \\ Technology (NTNU) \\ Faculty of Engineering Science and \\ Technology (IVT) \\ Norway \\ martin.steinert@ntnu.no
}

\author{
Ben Toscher \\ Norwegian University of Science and \\ Technology (NTNU) \\ Department of Industrial Economics \\ and Technology Management \\ Norway \\ benjamin.toscher@ntnu.no \\ Kevin Reuther \\ University of the West of Scotland \\ (UWS) \\ School of Business and Enterprise \\ United Kingdom \\ kevin.reuther@uws.ac.uk
}

\author{
Anh Nguyen Duc \\ University of South Eastern Norway \\ (USN) \\ Business school \\ Norway \\ anh.nguyen.duc@usn.no
}

\begin{abstract}
The search for a "best practice" of entrepreneurship has been a big part of the science of entrepreneurship of our millennium. Using text analysis, this article empirically investigates the way 756 entrepreneurs from three different cohorts conceptualize 2 of the 27 elements in such a suggested normative model. The two elements explored are "Core Competence" and "Unique Value Proposition". Our findings are that there may be two problems with the use of these elements. Firstly - the number of entries from each case suggest that entrepreneurs struggle with finding and settling on a "unique" statement for either of the two elements. Secondly, a percentage of the entrepreneurs seem to struggle to differentiate the two concepts from each other. Finally, there seem to be differences between the three investigated cohorts concerning the findings, where higher education and more experience may make it easier to utilize and understand Core Competence and Unique Value Proposition as parts of the entrepreneurial process
\end{abstract}

Keywords-Entrepreneurship, Core Competence, Unique Value Proposition, Business Idea, Business Model, Key Contribution, Key Market, Big Data, Data Warehouse

\section{INTRODUCTION}

In 2012, Scott Shane wrote an article in the Academy of Management Journal [1] reflecting on and summarizing the infamous article entitled "The promise of entrepreneurship as a field of research" [2], that he co-wrote with Venkataraman. In this article he addressed the major challenge of normatively trying to find a "best-practice of entrepreneurship:

\footnotetext{
"We did not intend to say that the entrepreneurial process is rational, planned, strategic, or even temporarily ordered, but merely that the entrepreneurial process has subprocesses. There may be no optimal entrepreneurial process, allowing for many equally effective approaches, which is an important issue for the field to explore. It is also possible that one approach may be optimal but that many entrepreneurs do not approach the process "the best way". This point has important ramifications for the fields desire to be normative."
}

This search for a set of best-practice subprocesses of entrepreneurship has motivated us to create a 7 step and 27 elements Normative Model of Entrepreneurship (NME), and the minimum viable product of the online test environment derived from it (NME-TE) [3]. This article attempts to cast a light on two of these elements; Core Competence (CC) and Unique Value Proposition (UVP). We empirically explore the characteristics of CC and UVP in 756 startup cases.

This paper is organized as follows: After this Introduction, Section II aims to familiarize the reader with the NME. Section III discusses the theoretical concepts of Core Competence and Unique Value Proposition and how entrepreneurial theory might expect them to relate to each other. Section IV introduces and describes the three research questions. Section V talks about the explorative and qualitative method chosen. Section VI describes the findings. Section VII discusses weaknesses and problems with the design. Section VIII contains the conclusions.

\section{THE NORMATIVE MODEL OF ENTREPRENEURSHIP AND THE TEST ENVIRONMENT}

From 2012 onwards, we have been gradually and incrementally developing the NME and the different minimum viable products of the NME-TH. Since then we have distributed more than 30 different white labelled entrepreneurship support platforms, serving over 10.000 entrepreneurial cases. The improvements and findings from these cases done throughout this period have resulted in the NME and NME-TH generation 1 being released in april 2019 [3].

The development of the NME has been based on six interlinked pillars of modern entrepreneurial theory [4]. We are starting with the concept of the Resource-Based View [5] [6], with special focus on Core Competence as a resource [7]. We then look at entrepreneurship as a nexus between entrepreneur and opportunity [2] and then try to build a bridge via the discussions around Effectuation [8] [9] [10] Bricolage [11] and Business Modelling [12] [13] [14] toward The Lean Startup Movement [15] [16]. We are aware that this does not provide a comprehensive overview of all entrepreneurshiprelated theories that have been part of the academic debate, but 
these are the ones considered especially valuable as a foundation for our approach towards an NME."

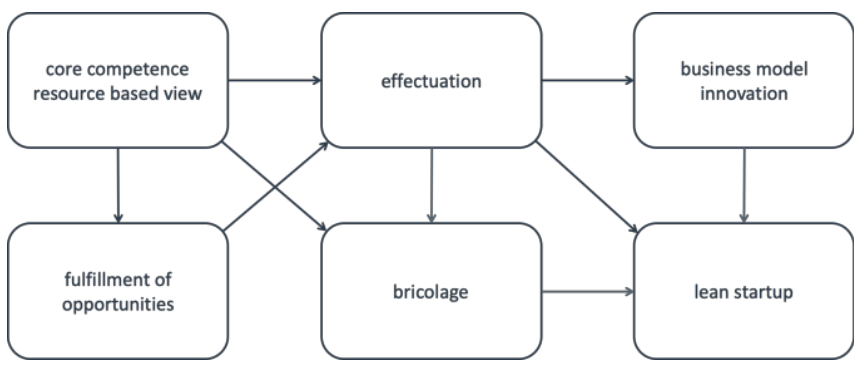

Figure 1: The six theoretical pillars

Based on these theories, and Shane's concept of entrepreneurial subprocesses, we are assuming that there are some main building blocks involved in most entrepreneurial projects. Also, it might make sense that these building blocks can be put in a logical or sequential order. If you develop a case, you would rather try to find the business idea before the business model, you would try to find your objectives before worrying about what to do to actually reach those objectives and the development of a financial forecast would typically be done after all those things are handled. After that, you would engage in a round of iterative learning and improvements of each step, meaning that you would have to go back in the sequence and change what you have done. Like Shane, we do not aspire to find one optimal entrepreneurial process. Neither do we suggest that all entrepreneurs work in a similar fashion. The NME is simply a starting point for a proposed model for empirically comparing the actions of a large number of entrepreneurs when having their sub-processes labelled in a structured fashion.

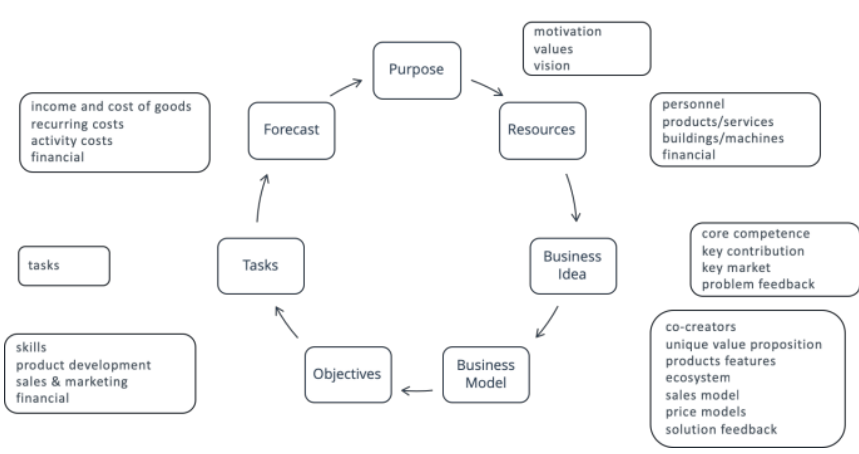

Figure 2: The Normative Model

The NME suggest that the entrepreneurial process starts with defining the purpose of the startup, following up with registering the initial resources available for the entrepreneur. Then the two strategy steps of defining the business ideas and business models of the case are followed by the project development steps of objectives, tasks and forecast. These steps are developed and improved in the structure of a Finite State Machine [17] or a set of interrelated Deming-cycles or PDCA-cycles [16], combining continuous redesign of the seven steps with documenting the actual results from the entrepreneurial case. We acknowledge that these steps cannot constitute the only perspective on entrepreneurial processes and that other steps might be added, or the sequence of some steps might be debatable. However, it is a useful starting point for our research and can also be the basis for further academic debate. The elaboration of the seven steps leads to 27 elements that constitute a more detailed version of our suggested entrepreneurial subprocesses [3]. By looking at different perspectives in each step, the entrepreneurial stage can be understood better through the connections among the perspectives. For example, the purpose of entrepreneurship can be seen from both vision, motivations and core values, which are interrelated and not separable from each other. As illustrated in Figure 2, we propose a normative model of entrepreneurship with seven steps and 27 elements.

\section{THE CONCEPTS OF CORE COMPETENCE AND UVP}

In this article, we have chosen to focus on two out of the 27 elements of the NME: Core Competence as one part of the Business Idea and Unique Value Proposition as one part of the Business Model.

The first one originates from Prahalad and Hamel [7], and is defined as " a harmonized combination of multiple resources and skills that distinguish a firm in the marketplace" [18]. As helpfully indicated by Alizadeh and Khormaei [19], they however do not belong to resources in the sense of 'factors of production', but are rather based on a competence view (see figure 3), and related to the innovativeness of the organization [20].

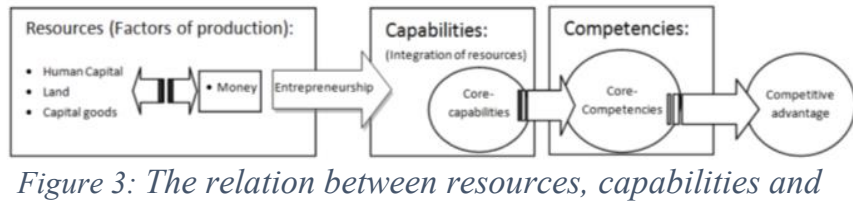
competencies.

In our model, this is therefore included as a part of the Business Idea step together with Key Market and Key Contribution.

As an example, Prahalad and Hamel [7] attribute the NEC corporation's ability to be competitive in fields of business as different as semiconductors, telecommunications, computing, and consumer electronics to viewing themselves as "a portfolio of core competencies - the company's collective knowledge about how to coordinate diverse production skills and technologies." Here they specifically point to the CC as reaching beyond individual products, services or even business units.

The Unique Value Proposition (UVP) is a somewhat more unclear concept, although it is one of the most used concepts in practical entrepreneurial coaching. The reason for this is that it is a centerpiece of Osterwalder and Pigneur's Business Model Canvas [13]. Here, the UVP is defined as "the bundle of products and services that create value for a specific Customer Segment".

Ash Maurya has developed a competing framework called "Lean Canvas". Here, the UVP is defined as: "A single, clear compelling message that states why you are different and worth buying" [21].

Steve Blank [15] writes that a Value Proposition is a "tendollar phrase describing a company's product or service. It's the what are you building and selling?"

Geoffrey Moore [22] has developed a whole framework where companies are supposed to fill in words in a sentencestructure to create their UVP. They are asked to start with their target customer, then add that customer's problem and need. Next, they are asked to add a general categorization of the products and services that the company provides to solve this 
problem or satisfy the need. Then the company should add the primary benefits of the given products or service, and also describe the advantages over the main competitor's products and services. Finally, the company is supposed to describe the primary differentiations of their products over the competitors' products.

Vlaskovits \& Cooper have developed a similar framework called Customer-Problem-Solution [23]. In their presentation, they ask an entrepreneur whom they are advising to put down the name of their customer, then the customer's problem and finally to describe the solution to the problem.

Concentrating on the UVP, we can see that five of the most read and used sources of advice to practical entrepreneurs are quite inconsistent with regard to what the UVP actually is.

Maurya and Blank connect it very clearly to the product, describing it more or less as a marketing statement or pay-off describing the differentiation of the product or service compared to the competition.

Osterwalder/Pigneur, Moore and Vlaskovits/Cooper do the same, but they are rather basing these product features on an understanding of the combination of the Key Contribution (a problem to solve) and a Key Market (target group who has this problem).

When we look at the CC and the UVP together, we can see that both are very useful concepts that are center stage of the business development of entrepreneurial projects. Furthermore, they have one clear similarity, and one very clear differentiation. Both from a theoretical point of view:

The Similarity lies in the term "Unique". Both terms are strongly linked on the precondition that they should be used to clearly differentiate the entrepreneur/offering from its competition. From this it follows that there cannot be a large number of such uniquenesses. The level of differentiation demanded from the terms makes it unlikely that someone could be able to have a large number of either CC's or UVP's.

The difference, however, is based on the object of analysis. The unique features defined under $\mathrm{CC}$ describe either the entrepreneur as an individual, or the entrepreneurs' company or organization. Following the definitions introduced before, they describe the abilities, assets or resources of the entrepreneur or the entrepreneurial organization on an overall level.

In contrast, the unique features defined under UVP relate to the products and/or services produced and marketed by the entrepreneur or organization. To a certain extent, there is an unclarity between the different theories about the degree to which these features should describe the physical functions of the product, or the satisfaction of the actual needs or problems of the entrepreneurs potential customers. [24]. There furthermore is the problem of one-product or one-service companies. In such cases, it can be difficult to differentiate between the uniqueness of the entrepreneur or company and the uniqueness of the product or service. Thinking of for instance one-person law-firms or consultants, you could claim that the sole employee/entrepreneur actually is the product. Unclarity may also arise in the situation where the products are not finalized. Both concepts are very often used in the preproduct stage of business development, where the entrepreneur may have defined a customer problem, but so far have not yet found a solution to the problem. They may have an un-tested minimum viable product [16] or even a very unclear vision on how to solve this problem, and the $\mathrm{CC}$ everything is built on may be equally unclear.

To clarify the difference between the terms: According to the theories we have been citing so far in this article, the logical order of developing a new product or service could be: 1) Start with the core competencies (abilities, assets or resources) of the entrepreneur. 2) Based on this (and without any bias based on having a ready-made product) find a combination of a Key Contribution (a problem to solve) and a Key Market (target group who has this problem). Verify that there is a real problem concerning a real group of potential customers. Then 3 ) try to develop a product or a service that has a set of distinct Unique Value Propositions that makes it stand out in the market place (defined by the Key Contribution and the Key Market) in comparison with all potential competitors. Then verify that it actually does so. This is also in accordance with Steve Blanks Customer development model [15].

In the next chapters we will present an empirical test showing how 756 entrepreneurial cases divided on three totally different cohorts actually use the two concepts of Core Competence and Unique Value Propositions.

\section{THE RESEARCH QUESTIONS}

Since this paper relies on the subjective understanding of the two terms CC and UVP and the interpretation of entrepreneurs' related statements, it might be challenging to acquire clear results of unrestricted significance. However, it enables us to find indications on whether the two terms are actually being used according to the theories.

The theory states that:

a) both the CC and the UVP should be reserved for truly "unique" features.

b) there is a difference between the concepts of $\mathrm{CC}$ and UVP.

c) the difference is related to what subject the statements refer to - where the $\mathrm{CC}$ relates to the entrepreneur/organization and the UVP relates to the products/services.

To validate that this is the way the entrepreneurs use the concepts, we ask three questions:

1) Q1) Do the entrepreneurs express their CC and UVP as "unique" or not?

2) Q2) Do the entrepreneurs separate between the CC and the UVP as of using the $\mathrm{CC}$ to describe the entrepreneur/organization and the UVP to describe the product/service?

3) Q3) There are variations between the three cohorts with regard to Q1 and Q2?

To operationalize this, we will measure:

- O1) The number of different suggestions of CC's and UVP's for each case, meaning how often entrepreneurs edited or changed these. A large number of CC's or UVP's per case could indicate that there are problems with the understanding of the demanded uniqueness of the terms, given that both 
terms are meant to be describing something truly special with the entrepreneur/organization or with the product/service.

- O2) What percentage of the cases use the CC to describe the entrepreneur/organization, and what percentage of the cases use the UVP to describe the product/service. A high percentage of cases would indicate that entrepreneurs use the two terms as intended in the theory. We will also look more closely at the specific language that are used in describing the CC and UVP by running a qualitative text analysis.

- $\quad \mathrm{O} 3)$ Here we measure the same variables as in $\mathrm{O} 1$ and $\mathrm{O} 2$, only separately for the three cohorts.

\section{The Test Design}

We have studied 756 entrepreneurial projects from 3 diverse entrepreneur cohorts that participate in our test. These participants come from diverse cultural, economic, and professional backgrounds. All of the participants are entrepreneurs, and all of the data comes from the NME-TH, with which they interact and develop their business idea.

The first Cohort consists of 125 Scandinavian Arts Entrepreneurs. These are working in cultural and creative industries and have the ambition to live off their talent by building a profitable business. These include entrepreneurs working in music, film, photography, games, architecture, design, advertising, cultural heritage and artistic activities. Participants gain insight into a practical and creative way to develop their business as well as access to good tools to build profitable operations. Of this cohort, approximately 30 participants are also students in a music management education program in Norway. The educational background of this group is somewhat varied, but most of them have some kind of higher education.

The second cohort consists of 202 Educational Technology Entrepreneurs who are participants in the University College London's educational technology incubator. The incubator provides business growth support and bespoke mentoring to small and medium sized enterprises (SMEs) in the education technology sector. All of these entrepreneurs have higher university education.

The third cohort consists of 429 South African Entrepreneurs aged between 18-35, all recruited from BroadBased Black Economic Empowerment background. They are participants in a 6-month program that offers improved operational processes and tools, access to business skills support, fit-to-purpose mentorship, financial and nonfinancial resources, and targeted market access. These entrepreneurs rarely have a university education.

All of these entrepreneurs have gone through training programs based on the Normative Model of Entrepreneurship, and they have been instructed to develop their business using the Test Environment. We got 756 responses, with 429 coming from the South African Youth group, 202 responses from the British Tech group and 125 responses from the Scandinavian Arts group.

With regards to the $\mathrm{CC}$, all entrepreneurs were trained in the concept of the Business Idea - consisting of Core Competence, Key Contribution and Key Market.

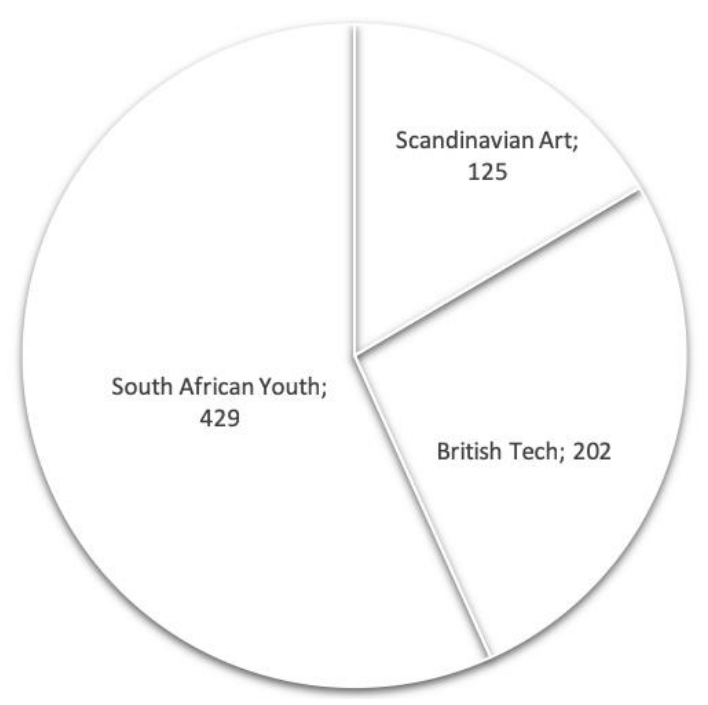

Figure 4: Total number of cases

For the $\mathrm{CC}$, a story about the Chinese basketball player Yao Ming was told to exemplify how being $229 \mathrm{~cm}$ tall is a core competence for being a basketball center. For the CC, the following support text was presented from the system:

"WHAT MAKES YOU UNIQUE? Here you should add what makes you better suited to solve the problem than anyone else. Why should the customer choose you? What will make it difficult for the competition to copy you?"

With regards to the UVP, it was presented as a part of the Business Model step, together with the co-creators, product features, eco-system, sales model and price model. They were specifically informed that the $\mathrm{CC}$ was supposed to be related to the entrepreneur and the organization - viewed from the customer problem perspective, whereas the UVP was supposed to be related to the product or to the solution perspective. As an example, the UVP of driving pleasure for BMW versus the UVP of traffic safety for Volvo was discussed. For the UVP the following support text was presented from the system:

"WHAT IS YOUR UNIQUE VALUE PROPOSITION? What is your unique selling point? What will separate you from your competitors?"

The output was then treated in three different processes:

1. Q1) All of the entries (cards) in the CC and UVP elements for each of the 743 cases were counted (There are 13 cases less than in $\mathrm{O} 2$ due to the time difference between the two tests). An average was calculated.

2. Q2) All of the text in the CC and UVP elements for each of the 756 cases was coded as 1,2 or 3 according to the following criteria:

Table 1: Coding of the CC and UVP elements

\begin{tabular}{|l|l|}
\hline (A) The CC is describing: & (B) The UVP is describing: \\
\hline $\begin{array}{l}\text { (1) The products/services } \\
\text { (2) The entrepreneur/ } \\
\text { organization }\end{array}$ & $\begin{array}{l}\text { (2) The products/services } \\
\text { entrepreneur/organization }\end{array}$ \\
\hline (3) Unclear or no answer & (2) Unclear or no answer \\
\hline
\end{tabular}


The combination of these answers was then categorized into 9 categories, and the number of entries in each category was calculated:

Table 2: Nine Categories

\begin{tabular}{|l|l|}
\hline Id & Category names \\
\hline 1 & Both CC and UVP describes the product/service \\
\hline 2 & $\begin{array}{l}\text { CC describes product/service, UVP describes the } \\
\text { entrepreneur/organization }\end{array}$ \\
\hline 3 & $\begin{array}{l}\text { CC describes product/service, unknown what UVP } \\
\text { describes }\end{array}$ \\
\hline 4 & $\begin{array}{l}\text { CC describes the entrepreneur/organization, UVP } \\
\text { describes the product/service }\end{array}$ \\
\hline 5 & $\begin{array}{l}\text { Both CC and UVP describes the } \\
\text { entrepreneur/organization }\end{array}$ \\
\hline 6 & $\begin{array}{l}\text { CC describes the entrepreneur/organization, } \\
\text { unknown what UVP describes }\end{array}$ \\
\hline 7 & $\begin{array}{l}\text { Unknown what CC describes, UVP describes the } \\
\text { product/service }\end{array}$ \\
\hline 8 & $\begin{array}{l}\text { Unknown what CC describes, UVP describes the } \\
\text { entrepreneur/organization }\end{array}$ \\
\hline 9 & $\begin{array}{l}\text { Unknown what CC describes, unknown what UVP } \\
\text { describes }\end{array}$ \\
\hline
\end{tabular}

It was of course not unproblematic to categorize the cases. These two examples show how it was done:

Case $9129^{1} \mathrm{CC}$ : "rinse free washing liquid soap, just wash and hang, few hours to dry up, we manufacture rinse free washing soap liquid, this kind of soap does not need any water to rinse your washing. It saves time and water usage; we focus on manufacturing chemicals using less water."

Case 9129 UVP: “we will add value to our customers by providing high quality, environmentally-friendly cleaning chemicals, services and products."

This candidate has related the $\mathrm{CC}$ to the product and the UVP to the product. This would place him in category 1 .

Case $9601 \mathrm{CC}$ : "experience of HR management, integrated solutions, management of our talent pool, experience in working with SMME's."

Case 9601 UVP: "experience, follow through, well researched tools, limited number of service providers, experience."

This candidate has related the $\mathrm{CC}$ to the entrepreneur and the UVP to the entrepreneur. This would place this particular candidate in category 5 .

We then collected all statements and merged them into two text files, one for the Core Competence and one for the Unique Value Proposition. The text files were translated to english where necessary, washed for typographic errors, and all text containing any kind of indicators of identity of persons, companies or geographies was removed for privacy reasons. The text files were then run into Leximancer ${ }^{2}$ to find logical concepts. The text files contained the following number of words:
Table 3: Number of Words per text file

\begin{tabular}{|l|r|}
\hline Element & \# of Words \\
\hline Core Competence & 23782 \\
\hline UVP & 12824 \\
\hline
\end{tabular}

Q3) Then the average number of entries (cards) in the CC and UVP elements was calculated per cohort. The category belonging to Q2 was calculated per cohort, and the statements were separated into six text files. One for each of the three cohorts for the $\mathrm{CC}$ and one for each of the three cohorts for the UVP. The files were then run into Leximancer, an automated content analysis software, to find logical concepts. We include an automated content analysis to perform exploratory analysis of the data to see if there are any unforeseen logical concepts inherent to the CC and UVP elements, based upon the entries provided by the entrepreneurs in our study. This automated content analysis produces both text concepts and concept maps. The text files contained the following number of words:

Table 4: Number of Words per text file per cohort,

\begin{tabular}{|l|l|r|}
\hline Cohort & Element & \# of Words \\
\hline Scandinavian Art & Core Competence & 4246 \\
\hline British Tech & Core Competence & 6517 \\
\hline South African Youth & Core Competence & 13019 \\
\hline Scandinavian Art & UVP & 2359 \\
\hline British Tech & UVP & 3033 \\
\hline South African Youth & UVP & 7432 \\
\hline
\end{tabular}

\section{FINDINGS}

We made the following observations:

Q1) The average number of CC entries done over the 743 cases was 4,36 entries per case. The average number of UVP entries done over the 743 cases was 1,89 entries per case. This is more than the 1 entry per case you would expect if the entrepreneurs fully related to the uniqueness requirement. Particularly for the $\mathrm{CC}$, the number of entries was high.

Q2) The distribution of the cases over the nine categories was as follows:

\section{Table 5: Distribution to the Categories}

\begin{tabular}{|l|r|r|}
\hline Category \# - Description & $\begin{array}{r}\text { \# of } \\
\text { Case } \\
\text { s }\end{array}$ & $\begin{array}{r}\text { \% of } \\
\text { entire } \\
\text { sample }\end{array}$ \\
\hline $\begin{array}{l}\text { 1 - Both CC and UVP describes the } \\
\text { product/service }\end{array}$ & 172 & $23 \%$ \\
\hline $\begin{array}{l}\text { 2 - CC describes product/service, } \\
\text { UVP describes the } \\
\text { entrepreneur/organization }\end{array}$ & 23 & $3 \%$ \\
\hline $\begin{array}{l}\text { 3 - CC describes product/service, } \\
\text { unknown what UVP describes }\end{array}$ & 40 \\
\hline $\begin{array}{l}4 \text { - CC describes the } \\
\text { entrepreneur/organization, UVP } \\
\text { describes the product/service }\end{array}$ & 258 & $34 \%$ \\
\hline
\end{tabular}




\begin{tabular}{|l|r|r|}
\hline $\begin{array}{l}5 \text { - Both CC and UVP describes the } \\
\text { entrepreneur/organization }\end{array}$ & 42 & $6 \%$ \\
\hline $\begin{array}{l}\text { 6 - CC describes the } \\
\text { entrepreneur/organization, unknown } \\
\text { what UVP describes }\end{array}$ & 112 & $15 \%$ \\
\hline $\begin{array}{l}7 \text { - Unknown what CC describes, } \\
\text { UVP describes the product/service }\end{array}$ & 72 & $10 \%$ \\
\hline $\begin{array}{l}\text { 8 - Unknown what CC describes, } \\
\text { UVP describes the } \\
\text { entrepreneur/organization }\end{array}$ & 12 \\
\hline $\begin{array}{l}\text { 9 - Unknown what CC describes, } \\
\text { unknown what UVP describes }\end{array}$ & 25 & $3 \%$ \\
\hline Total & 756 & $100 \%$ \\
\hline
\end{tabular}

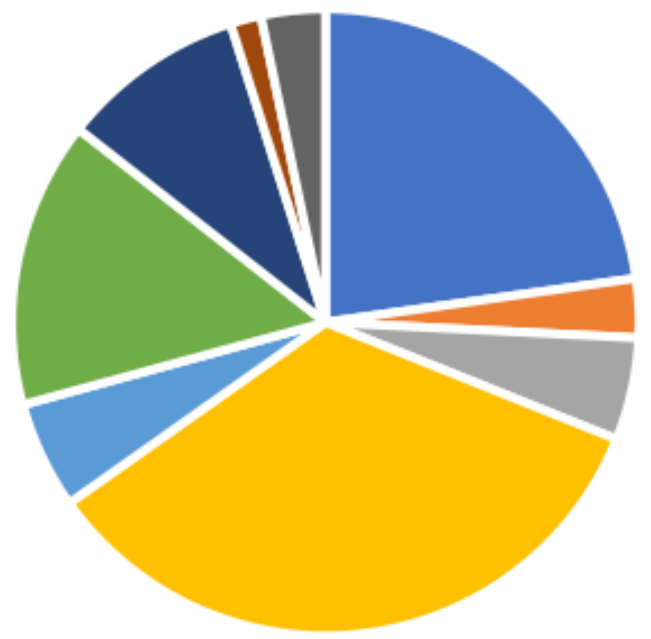

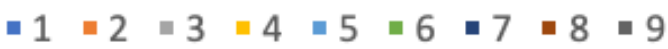

Figure 5: Distribution to the Categories, Graph

This shows that no more than $54 \%$ of the entrepreneurs clearly describe the entrepreneur/organization in the $\mathrm{CC}$ element. The remaining $46 \%$ either describes the product/service, give an unclear description or give no description at all.

Similarly, no more than $66 \%$ of the entrepreneurs clearly describe the product/service in the UVP element. The remaining 34\% either describe the entrepreneur/organization, give an unclear description or give no description at all. Automated content analysis via Leximancer produces both higher order text concepts and concept maps which helps us to explore and to understand how the entrepreneurs conceptualize the CC and UVP differently.

Word-Like
experience
unique
business
service
quality
clients
customer
services
product
time
knowledge
education
products
offer
company
management
industry
expertise
team
network
design
work
skills

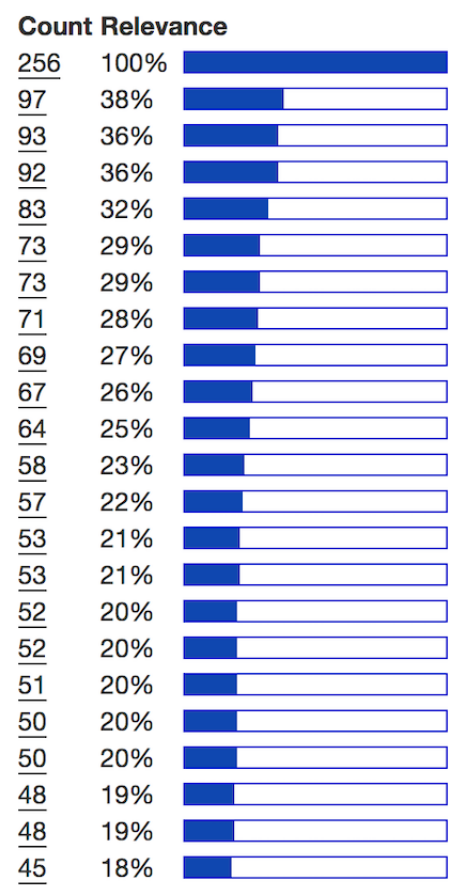

Figure 6: Text Concepts - CC

The text concepts show that the CC texts have a set of concepts you would expect to be related to a description of a person or an organization, like "experience", "knowledge" and "education". Here the term "experience" is by far the most common concept at $100 \%$. On the other hand, there are also concepts that you would relate to a product-like thing or an object, like "quality" or "design". However, the dominance by the concept of "experience" leads us believe that the entrepreneurs in our study strongly associate experience and experiential knowledge with their core competence. Indeed, it may be true that in all walks of life, whether business or personal, all "experience" is unique - which fits tightly with how the entrepreneurs were prompted to answer.

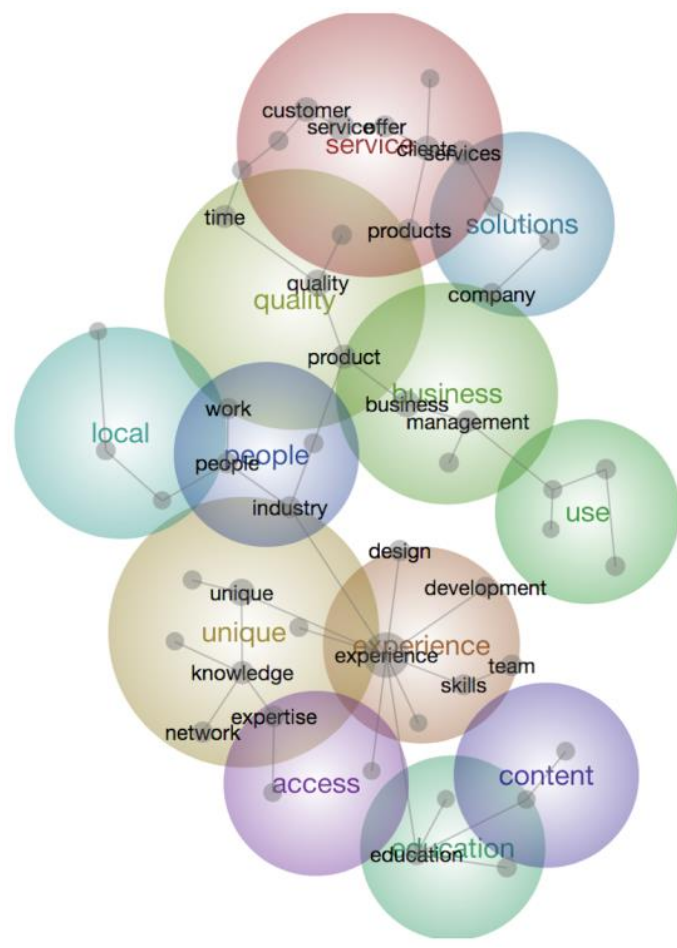

Figure 7: Concept Map for CC, Graph 
Similarly, the UVP texts have concepts that would logically relate to a product or a service, like "quality", "product(s)", "delivery", and "price"/" affordability"/" value". We note that quality is $100 \%$ relevant for this cohort. But, even if there are not so many as in the CC element, there are also references to "Experience" - which most likely relates to a person or an organization. In addition, we find the cluster of "quality", "solutions", "products" and service, that most likely relates to the product-service axis as something unique to the organization. This may be somewhat problematic, as the CC should be describing core skillsets enabling the organization to develop products and services, not the products and services in themselves [7].

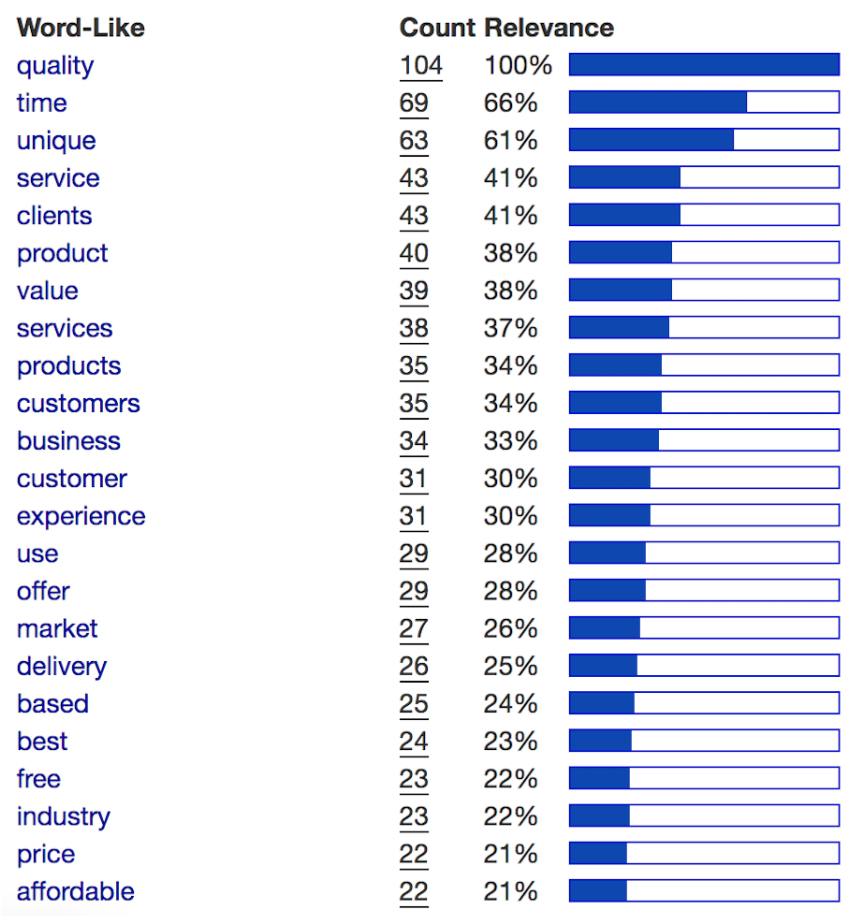

Figure 8: Text Concepts - UVP

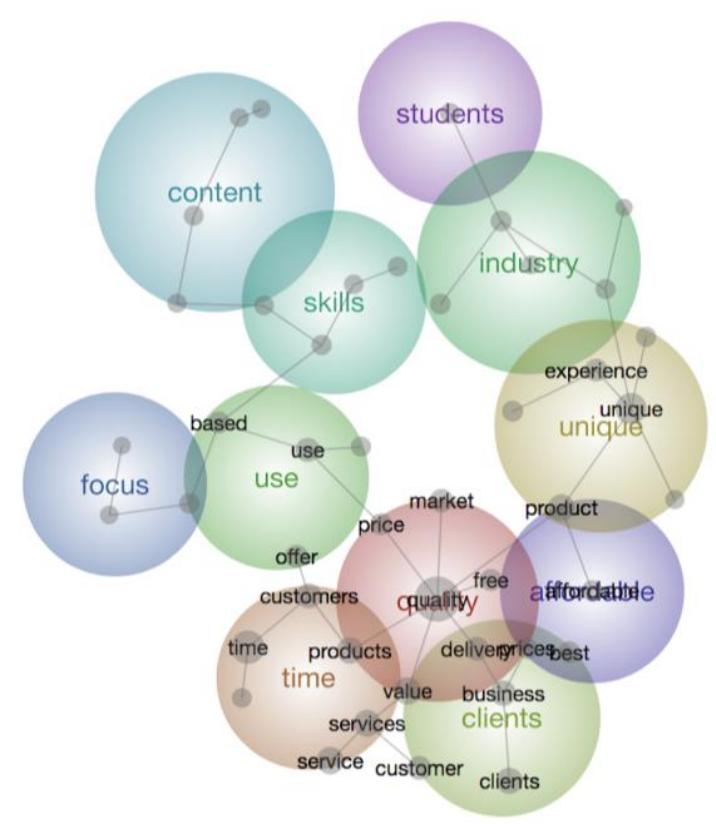

Figure 9: Concept Map for UVP, Graph
Q3) When separating the different analyses on the three cohorts, we get the following results:

Table 6: Average count of entries - cohorts

\begin{tabular}{|l|c|c|}
\hline Cohort & Average CC & Average UVP \\
\hline Young South African & 3,75 & 1,59 \\
\hline Arts & 4,07 & 1,42 \\
\hline Tech & 5,92 & 2,90 \\
\hline Sum & 4,36 & 1,89 \\
\hline
\end{tabular}

First, we see that the Tech entrepreneurs create a higher average number of entries per case on both the CC and UVP elements than both the other two groups.

Table 7: Distribution to Categories, cohorts

\begin{tabular}{|l|c|c|c|c|}
\hline Categories & Arts & Tech & YSA & All \\
\hline Category 1 & $9 \%$ & $11 \%$ & $32 \%$ & $23 \%$ \\
\hline Category 2 & $1 \%$ & $0 \%$ & $5 \%$ & $3 \%$ \\
\hline Category 3 & $3 \%$ & $4 \%$ & $7 \%$ & $5 \%$ \\
\hline Category 4 & $56 \%$ & $44 \%$ & $23 \%$ & $34 \%$ \\
\hline Category 5 & $6 \%$ & $2 \%$ & $7 \%$ & $6 \%$ \\
\hline Category 6 & $16 \%$ & $31 \%$ & $7 \%$ & $15 \%$ \\
\hline Category 7 & $5 \%$ & $6 \%$ & $13 \%$ & $10 \%$ \\
\hline Category 8 & $2 \%$ & $0 \%$ & $2 \%$ & $2 \%$ \\
\hline Category 9 & $2 \%$ & $2 \%$ & $4 \%$ & $3 \%$ \\
\hline & $100 \%$ & $100 \%$ & $100 \%$ & 100 \\
& & & & \multicolumn{2}{c}{} \\
\hline
\end{tabular}

When we look at the distribution between the nine categories, we see that the young South African entrepreneurs seem to be higher on category 1 (Both CC and UVP describes the product/service) and lower on category 4 (CC describes the entrepreneur/organization, UVP describes the product/service).

The Arts entrepreneurs seem to be higher on category 4, while the Tech entrepreneurs apparently are higher on category 6 (CC describes the entrepreneur/organization, unknown what UVP describes). When looking closer on this, it seems to be related to a higher number of blank entries in the UVP element for the Tech entrepreneurs.

We also note that Tech entrepreneurs had the lowest representation in category 5 , indicating that they are more able to distinguish themselves as entrepreneurs from the product/service they are creating. The nature of the cultural industries, where an individual name or identity is a brand with associated aesthetic value, could explain why Arts entrepreneurs tended more to have the CC and UVP describe the entrepreneur.

When we start looking at the text concepts separated on the three cohorts, we first of all find what we would expect. The Arts entrepreneurs have a higher content of art-specific concepts like "art", "cultural" and "music". The Tech entrepreneurs have concepts like "teaching/teachers" and "skills". Since they specialize on education technology that 
should not be surprising. Apart from that, the findings seem to be in line with what we learned in Q2.

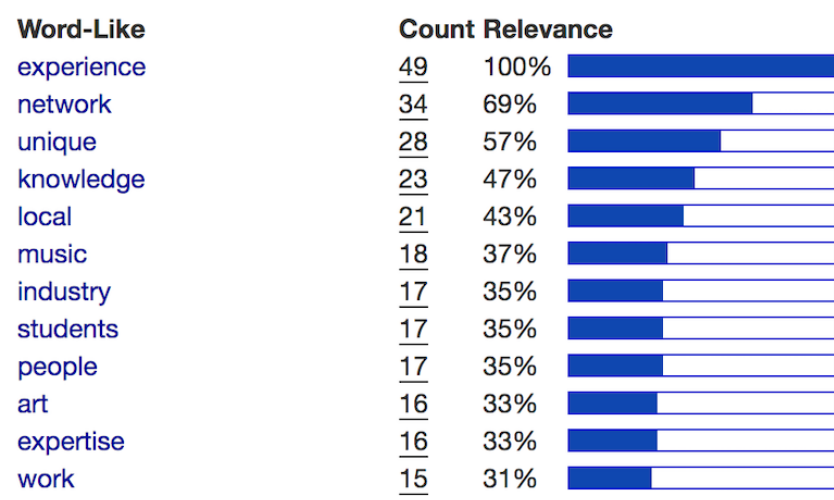

Figure 10: Text Concepts - CC, Arts

When we look at the $\mathrm{CC}$ for the Arts entrepreneurs, we see that most of the concepts are consistent with describing an entrepreneur. Concepts like "experienced" and "network" could very well be useful Core Competences to have in the arts business.

\begin{tabular}{lllll} 
Word-Like & \multicolumn{3}{l}{ Count Relevance } \\
unique & $\frac{27}{16}$ & $100 \%$ & \\
experience & $\frac{16}{15}$ & $56 \%$ & \\
quality & $\frac{13}{13}$ & $48 \%$ & \\
industry & $\frac{13}{13}$ & $48 \%$ & \\
music & $\underline{12}$ & $44 \%$ & \\
place & $\underline{11}$ & $41 \%$ & \\
cultural & $\underline{10}$ & $37 \%$ & \\
knowledge & $\underline{10}$ & $37 \%$ & & \\
students & $\underline{9}$ & $33 \%$ & & \\
artists & $\underline{8}$ & $30 \%$ & & \\
art & & & \\
food & & &
\end{tabular}

Figure 11: Text Concepts - UVP, Arts

The concepts described by the Arts entrepreneurs in the UVP element, is also consistent with the delivery of art as a service. Here terms like "experience" and "quality" fits well with this.

\begin{tabular}{|c|c|c|}
\hline Word-Like & Cou & Relevance \\
\hline experience & 112 & $100 \%$ \\
\hline education & $\underline{50}$ & $45 \%$ \\
\hline learning & $\underline{46}$ & $41 \%$ \\
\hline team & 36 & $32 \%$ \\
\hline content & 28 & $25 \%$ \\
\hline teaching & $\underline{26}$ & $23 \%$ \\
\hline unique & $\underline{26}$ & $23 \%$ \\
\hline skills & $\underline{25}$ & $22 \%$ \\
\hline research & $\underline{24}$ & $21 \%$ \\
\hline knowledge & $\underline{24}$ & $21 \%$ \\
\hline teachers & $\underline{22}$ & $20 \%$ \\
\hline tech & 21 & $19 \%$ \\
\hline
\end{tabular}

The Tech entrepreneurs $\mathrm{CC}$ is a bit harder to separate from the UVP, as their deliveries often can be described by similar concepts to the ones describing the knowledge or skillset of the entrepreneur. Additionally, we note that the Tech cohort had the largest representation in category $6(31 \%)$, indicating relative unclarity over the UVP concept. Here we see that

terms like "learning" and "skills" are represented in both elements.

Word-Like
learning
content
platform
students
unique
skills
market
time
based
teachers
data
offer

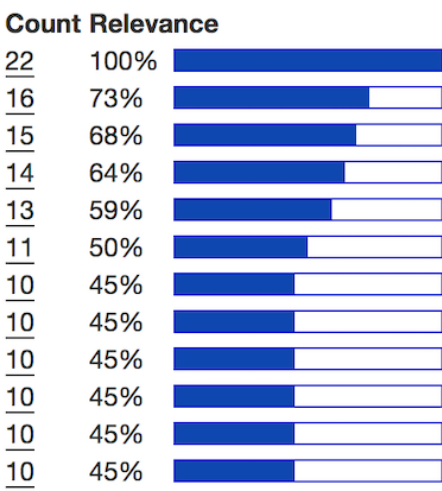

Figure 13: Text Concepts - UVP, Tech

Here we see that the Tech entrepreneurs have a concept like "skills" included in the UVP. This may be due to the fact that "skills" in this context may relate to the product or service of the Tech entrepreneurs, which is presumably a technology for knowledge transfer. Thus, we infer they are not referring the skillset of the entrepreneurs.

Word-Like
service
services
clients
customer
business
quality
time
products
offer
product
experience
client

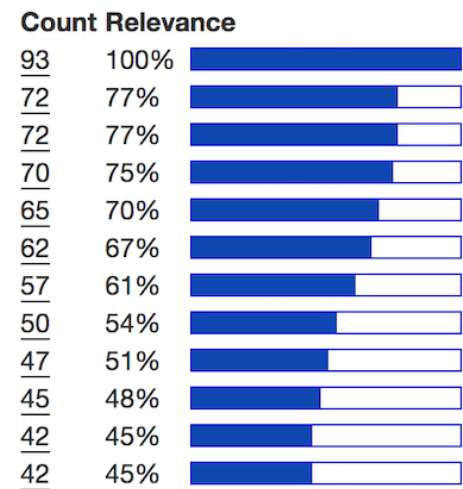

Figure 14: Text Concepts - CC, YSA

The main finding in the text analysis of the YSA cohort, is that we lack the concept of "experienced", even if that have been the most common concept in the other two cohorts. This is especially relevant given the age (18-35 years old) and background of the cohort.

Word-Like
quality
time
clients
service
services
value
products
customer
business
customers
product
client

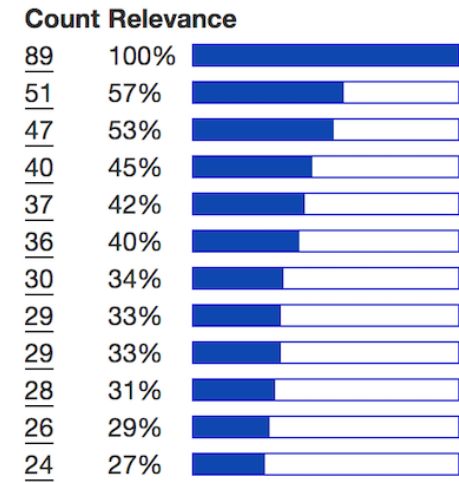

Figure 15: Text Concepts - UVP, YSA

\section{THREATS TO VALIDITY}

The data used in the course of this paper is based on a Minimum Viable Product version of the NME-TE. The main purpose of this version of the NME-TE has been to learn as 
much as possible, e.g. about how entrepreneurs might use the test environment, before launching Generation 1 in April 2019. Given the provisional nature of the NME-TE at the time of data gathering, the findings based on this data may not yet reflect the full potential of our approach and we do not wish to make any dogmatic conclusions on this basis. Since the Test Environment generates a steady stream of data, it is possible to repeat any experiment at all times and it therefore allows the elimination of potential problems.

The first possible bias concerns how the entrepreneurs have been instructed and trained to use the Test Environment. We have attempted to train the three cohorts as identical as possible. Whenever possible, the training has been done by the same people and the same presentations have been used. The supporting text and video material used has been identical, although there is an option to get it translated to different languages. The preparation of the different entrepreneurs therefore may have minor variations. Additionally, the entrepreneurs' conceptualizations of the elements, such as CC and UVP, are influenced by the training and the support texts. Whereas we attempted to deliver a uniform training to all participants, we nevertheless acknowledge that the words provided by the entrepreneurs are influenced by our own theoretical understanding of these elements (CC and UVP) and the subsequent building of the NME-TE and that training and support texts have a potential for optimizations to serve our future research.

Related to this is our own ability to explain the difference between the Core Competence and the Unique Value Proposition. We have focused on explaining the use of the terms, but we have not used the term "Core Competence" in the support text, as we fear it may make it harder to understand that a CC can be an asset or a motivation that is not limited to the conventional understanding of the term "competence" as something solemnly relating to knowledge. Improving the support is of course one of the main motivations for this research.

The next possible bias concerns the coding of the cases. Due to limitations in time and resources, the coding has been done by one individual (the first author), and a coding software has not been used. We still think that this part of the research gives relevant results, but we will consider redoing the experiment using a more systematic coding approach together with the next release of the NME-TE.

In addition to this, there are two minor aspects to be mentioned. First, the count of entries when answering Q1 is done with 13 fewer cases than when answering Q2. This is due to these cases being deleted from the NME-TE by the entrepreneurs in the time between test 2 and 1. Secondly, related to the counting of the entries when answering Q1, there may be more than one individual entering cards in some of the cases. In the current version of the NME-TE, we technically cannot control for this. More people may of course generate more entries, although the consolidation of the entries into just one CC and one UVP entry is encouraged.

\section{VIII.CONCLUSIONS}

Given the nature of the NME-TE at its recent state and the data it provides, we consider it appropriate to be cautious in developing sound conclusions and we offer some basic implications instead:
Q1) The average number of 4,36 CC entries per case suggests that there is a potential for improvement in how the entrepreneurs understand that a Core Competence should be something really unique. The average number of 1,89 UVP entries per case points in a similar direction, although less clear. Ideally, both these numbers should move toward 1 as the entrepreneurial concepts matures, and their identity becomes clearer.

Q2) There seems to be a tendency to sometimes create descriptions of uniquenesses concerning the product and services as a part of the CC. To a somewhat smaller degree, but still absolutely present, there seems to be a tendency to sometimes create descriptions of uniquenesses concerning the entrepreneur and the entrepreneurial organization as a part of the UVP.

In general, this might indicate that even though the $\mathrm{CC}$ and UVP elements are very important contributions to the Normative Model of Entrepreneurship, they can sometimes appear as too theoretical and difficult to differentiate to the average entrepreneur. There furthermore are indications that the entrepreneurial ecosystem would benefit if academics and practical entrepreneurs could try to simplify the concepts together and explain it in a better or more comprehensive way.

Q3) It seems that in particular education and experience to a certain degree make it easier to separate between the CC and the UVP. The young South African entrepreneurs are the youngest cohort with the least formal education. They were the ones who had the most problems with describing the entrepreneur or organization in the $\mathrm{CC}$ element and the product or service in the UVP element. They only had $23 \%$ in category 1 (Both CC and UVP describes the product/service) compared to $34 \%$ in the total population. Given that this cohort could be very representative for a large number of young entrepreneurs in developing countries that will come in the near future, it may be a place where further research is warranted.

The interesting thing is that the Tech Entrepreneurs, who all have higher education, were the ones who created the most entries in both the CC and the UVP elements. This is counterintuitive to what we would expect, based on the education level of the entrepreneurs. This phenomenon warrants further research.

Irrespectively, we have attempted to demonstrate our efforts in utilizing our test environment to further develop the understanding of how different types of entrepreneurs, conceptualize two specific elements of an entrepreneurial model. As we are launching the next generation of the NMETE, we will systematically work our way through more of the elements, in order to shed lights on strengths and weaknesses with the concepts currently being used in the knowledge transfer to the future value creators in the entrepreneurial ecosystem.

\section{REFERENCES}

[1] S. Shane, "Reflections on the 2010 'AMR' Decade award: Delivering on the promise of entrepreneurship as a field of research.," Acad. Manage. Rev., vol. 37, pp. 10-20, 2012.

[2] S. Shane and S. Venkataraman, "The Promise of Entrepreneurship as a Field of Research," Acad. Manage. Rev., vol. 25, pp. 217-227., 2000.

[3] Y. Dahle, M. Supphellen, and M. Steinert, "Searching for a normative model of entrepreneurship," This Artic. Prod.

[4] Y. Dahle, N. Anh, M. Steinert, and K. Reuther, "Six pillars of modern entrepreneurial theory," 
[5] B. Wernerfelt, "A Resource-based View of the Firm," Strateg. Mark. J., vol. 5, pp. 171-180, 1984.

[6] J. Barney, "Firm Resources and Sustained Competitive Advantage.," $J$. Manag., pp. 99-120, 1991.

[7]C. K. Prahalad and G. Hamel, "The Core Competence of the Corporation," Harv. Bus. Rev., p. 17, 1990.

[8] S. Sarasvathy, "Causation and Effectuation: Toward a Theoretical Shift from Economic Inevitability to Entrepreneurial Contingency," Acad. Manage. Rev., vol. 26, pp. 243-263, 2001.

[9] S. D. Sarasvathy and S. Venkataraman, "Strategy and Entrepreneurship: Outlines of an untold story.," in Strategic Management Handbook, 2000

[10] H. A. Simon, "Cognitive Science: The Newest Science of the Artificial," Cognitive. Sci., vol. 4, pp. 33-46, 1980.

[11] T. Baker and R. E. Nelson, "Creating Something from Nothing: Resource Construction through Entrepreneurial Bricolage," Adm. Sci. Q., vol. 50, pp. 329-366, 2005.

[12] A. Osterwalder, Y. Pigneur, and C. L. Tucci, "Clarifying Business Models: Origins, Present, and Future of the Concept," Commun. AIS, vol. 15, 2005.

[13] A. Osterwalder and Y. Pigneur, Business Model Generation. Hoboken, New Jersey: Wiley, 2010.

[14] C. Zott and R. Amit, Business Model Design: An Activity System Perspective", Long Range Plann., vol. 43, pp. 216-226, 2010.
[15] S. G. Blank, Four steps to the epiphany: successful strategies for products that win, 3rd ed. California: S. G. Blank, 2007.

[16] E. Ries, Lean Startup. Stanford, California: Crown Business, 2011.

[17] W. McCulloch and W. Pitts, "A logical calculus of the ideas immanent in nervous activity," Bull. Math. Biophys., vol. 5, p. 19, 1943.

[18] C. W. L. Hill, G. R. Jones, and M. A. Schilling, Strategic Management: Theory \& Cases: An Integrated Approach. Cengage Learning, 2014.

[19] Y. Alizadeh and R. Khormaei, "A Framework to identify the CoreCompetency of a SME; Case of Lensbaby LLC," presented at the IEEE International Technology Management Conference, Dallas, TX USA, 2012. [20] J. Forsythe and R. Khormaei, "Innovation topology: The dimensions and their characteristics that drive innovation.," presented at the Technology Management in the Energy Smart World, 2011, pp. 1-10.

[21] A. Maurya, Running Lean. Sebastopol, California: O'Reilly, 2012.

[22] G. Moore, Crossing the chasm. New York, NY, USA: Harper Collins Publishers, 1995.

[23] B. Cooper and P. Vlaskovits, The Lean Entrepreneur: How Visionaries Create Products, Innovate with New Ventures, and Disrupt Markets. John Wiley \& Sons, 2013.

[24] B. T. Christensen, L. J. Ball, and K. Halskov, Analyzing Design Thinking: Studies of Cross-Cultural Co-Creation. CRC Press, 2017 